\title{
A Literature Review of Attentional Biases amongst Individuals with Substance Dependency: Individual Differences and Modulating Factors
}

\author{
Melvyn Zhang ${ }^{1,2, *}$, Daniel S.S. Fung ${ }^{3(D)}$ and Helen Smith ${ }^{1}$ \\ 1 Family Medicine and Primary Care, Lee Kong Chian School of Medicine, Nanyang Technological University, \\ Singapore 308232, Singapore; h.e.smith@ntu.edu.sg \\ 2 National Addiction Management Service, Institute of Mental Health, Singapore 539747, Singapore \\ 3 Institute of Mental Health, Singapore 539747, Singapore; daniel_fung@imh.com.sg \\ * Correspondence: melvynzhangweibin@gmail.com
}

Received: 7 October 2020; Accepted: 3 December 2020; Published: 4 December 2020

\begin{abstract}
Introduction: Advances in experimental psychology have led to a better understanding of automatic, unconscious processes, referred to as attentional biases. Despite the growing evidence from meta-analytical studies, we still do not understand why some individuals have a greater magnitude of these biases, and why others have none. There has been little focus on elucidating individual differences and task parameters that affect the overall magnitude of the biases. In this opinion piece, we will attempt to identify these. We will then discuss both the research and clinical implications. Methods and Analysis: To identify the factors that modulated the magnitude of attentional biases across all the substance disorders (i.e., opioid use, cannabis use, and stimulant-use disorders), we performed a search using the bibliographic databases PubMed and MEDLINE. The search terminologies "attention bias" or "cognitive bias" or "approach bias" or "avoidance bias" were used when we looked for relevant articles. Results: It was evident from the published literature that several individual differences and factors modulated the magnitude of baseline biases. Across opioid, cannabis, and stimulant-use disorders, the most common individual differences identified were the severity of the dependence and the quantity of substance used. For both opioid and cannabis disorders the timing of stimulus presentation influenced the detection of attentional bias; it appeared that short stimulus timing was better able to detect attentional bias. Other identified individual differences included subjective craving and impulsiveness. The results highlight several research and clinical implications. Conclusions: The discovery of these individual differences and factors of the task paradigm that affect the magnitude of attentional biases will help in the future conceptualization of attention-bias-modification intervention.
\end{abstract}

Keywords: attention bias; cognitive bias; psychiatry

\section{Introduction}

Advances in experimental psychology have led to a better understanding of automatic, unconscious processes, referred to as attentional biases [1]. Such biases are present in several disorders, including depressive and anxiety disorders [1], but our interest is in examining these biases specifically for substance disorders. In the context of substance dependency, attentional biases refer to the automatic tendencies for attention to be preferentially directed towards substance-related cues [1,2]. Thus, individuals with addictive disorders will be more attracted to substance-related cues in their natural environment [2]. This attraction can result in a partial slip or full relapse back to addictive behavior. These biases arise when the chronic usage of substances results in increased automatic processing of substance-related cues, 
and corresponding inhibition of the normal cognitive control processes [3]. These biases are typically assessed by means of indirect measures (i.e., measures of reaction time) using tasks like the visual probe task [4]. When the visual probe task is used for the assessment of biases, probes replace both the drug and neutral stimuli in the same ratio (50:50). Modification of biases involves pairing the probe with the neutral stimuli $100 \%$ of the time, in order to effect bias retraining [4]. Conventional psychotherapies for relapse prevention, such as cognitive behavioral therapy, have limited impact as they only address cognitive control processes. In our previous review, we examined 38 studies involving participants with opioid, stimulant, or cannabis-use disorders, and found attentional biases are consistently observed in the studies involving these disorders [4]. More recently, MacLean et al. (2018) [5] conducted a meta-analysis focusing only on the attentional biases of opioid users and reported the presence of robust attentional biases. In another meta-analysis, $\mathrm{O}^{\prime} \mathrm{Neill}$ et al. (2020) [6] focused on individuals with cannabis-use disorders and found greater attentional biases amongst cannabis users compared with controls.

Despite the growing evidence from these meta-analytical studies, none of these prior studies have highlighted individual differences in attentional biases amongst sampled individuals with addictive disorders. We still do not understand why some individuals have evidence of biases when first assessed by means of an attention-bias assessment tool (baseline biases), and why some individuals have a larger magnitude of attentional bias at baseline. The absence of baseline biases amongst some substance users was evident in our previous study (Zhang et al., 2019) [7] evaluating the feasibility and acceptability of a mobile attention-bias-modification intervention. We found that $53 \%$ of the sampled individuals did not have baseline biases [7,8]. Previously MacLean et al. (2018) [5] had highlighted that individuals diagnosed with opioid use disorder had baseline biases, but non-dependent users of prescription opioids did not exhibit such biases. Other studies (e.g., Bearre et al. (2007) [9] and Fadardi et al. (2010) [10]) have reported a dose-dependent relationship between the quantity of opioids used and the magnitude of attentional biases observed. In 2013, Garland et al. [11] suggested that the presence or absence of baseline biases was associated with the stimulus timings used in the assessment of attention bias. Using the visual probe paradigm, they observed that a short stimulus timing interval of 200 rather than 2000 milliseconds was better able to capture attentional biases amongst opioid-using individuals. Similarly, for cannabis-use disorders, whilst O'Neill et al. (2020) [6] have demonstrated in their meta-analytical study the presence of attentional biases, factors that could have modulated the presence and the magnitude of biases were not explicitly highlighted. For example, Field et al. (2006) [12] investigated, in their prior study the relationship between the severity of cannabis dependence and attentional biases for cannabis-related stimuli, and found that the attentional bias was dependent on the frequency of cannabis use and also the subjective craving scores.

It remains of importance to examine these individual differences. Individual differences could affect the effectiveness of any attention bias modification intervention; and an understanding of individual differences could help in the personalization of the intervention, and also help in improving the ability of the intervention in modifying attentional biases (Dennis-Tiwary et al., 2017) [13]. With a knowledge of these individual differences, we will be better able to identify individuals who are more suited to receive such intervention, with certainty that there might be resultant changes in the magnitude of their biases. In this literature review, we will attempt to identify some of these individual differences that affect whether biases are present at baseline, and the corresponding magnitude of biases. We will also identify other factors relating to the nature of the task paradigms that affect the magnitude of attentional biases. We will then present and discuss some of the research and clinical implications.

\section{Methods}

To identify the factors that modulated the magnitude of attentional biases across all the substance disorders (i.e., that of opioid use, cannabis use, and stimulant-use disorders), we performed a search using the bibliographic databases PubMed and MEDLINE. The search terminologies, along with quotes "attention bias" or "cognitive bias" or "approach bias" or "avoidance bias" were used when we looked 
for relevant articles. We searched the databases from inception till 5 August 2020, and the search yielded 745 articles for attention bias, 1339 for cognitive bias, 168 for approach bias, and 34 for avoidance bias. Articles were only included if they discussed cognitive bias modification in the context of substance-use disorders, specifically those of illicit substances, namely opioids cannabis, and stimulant. In the subsequent three paragraphs, we will highlight what we found for opioid-use, cannabis-use, and stimulant-use disorders.

\section{Attentional Bias in Opioid-Use Disorders}

For opioid-use disorders, previous research has found differences in the magnitude of attentional biases amongst users and non-users, and amongst those with different severities of opioid addiction. Fadardi et al. (2010) [10] examined a cohort of 53 Iranian drug-abusers on methadone maintenance therapy and 71 non-abusers. They reported that drug-users had higher biases for drug-related stimuli, even after controlling for effects such as age and education. Similar findings were reported in the studies of Constantinou et al. (2010) [14] and Bearre et al. (2007) [9]. Constantinou et al. (2010) [14] examined attentional biases and cravings amongst current users of opioids, ex-users of opioids, and non-users. Current users consisted of individuals undergoing methadone maintenance treatment; ex-users consisted of abstinent participants attending programs, and non-users those who have never used opioids. They found that those who were currently abusing had a greater magnitude of attentional biases. They found that ex-users exhibited a bias away from the drug-related stimulus, which was related to their total duration of abstinence. Bearre et al. (2007) [9] reported a relationship between dependence severity (based on the monthly frequency of heroin used, via inhalation or injection) and the overall attentional biases. More recently, a meta-analytical study by MacLean et al. (2018) [5] concluded that individuals with diagnosed opioid dependence exhibited attentional biases, but these were not found in non-dependent prescription-opioid users, suggesting that the amount of substance used is a factor in modulating the strength of attentional biases.

Impulsiveness, cravings, temptations to use, and the stimulus timings of the visual probe task have been observed to affect attentional biases in opioid users. Anderson et al. (2013) [15] found attentional biases to be positively related to impulsiveness, but negatively related to the visual working-memory capacity. The observations of Water et al. (2012) [16] suggests that cravings and temptations to use might affect the magnitude. In their study they examined participants' affect and cognition before and during a temptation episode, and found elevated attentional biases during the temptation episodes, and the magnitude of biases was elevated $1 \mathrm{~h}$ prior to the temptation episode. Garland (2013) [11] investigated whether variations in the stimulus timings for the visual probe task impacted on the magnitude of attentional biases and reported that attentional biases were present only when stimuli were presented for short intervals of 200 milliseconds, instead of 2000 milliseconds. Demographic variables, such as gender were investigated to determine if they accounted for the differences in attentional biases amongst drug-abusers and non-abusers by Fadardi et al. (2010) [10]. The authors did not report them to influence biases. Moreover, the presence of attentional biases in an Iranian sample of participants also demonstrates that biases are culture-free [10]. Table 1 provides a brief overview of the articles identified and the factors highlighted. 
Table 1. Overview of individual differences and factors modulating biases in opioid-use disorders.

\begin{tabular}{|c|c|c|}
\hline Studies & $\begin{array}{c}\text { Individual Differences/Factors } \\
\text { Modulating }\end{array}$ & Main Findings \\
\hline Fadardi et al. (2010) [10] & $\begin{array}{l}\text { Substance dependency/amount of } \\
\text { substance used }\end{array}$ & $\begin{array}{l}\text { Drug-users had greater biases for } \\
\text { drug-related stimuli, even after } \\
\text { controlling for effects such as age } \\
\text { and education }\end{array}$ \\
\hline Constantinou et al. (2010) [14] & $\begin{array}{l}\text { Substance dependency/amount of } \\
\text { substance used }\end{array}$ & $\begin{array}{c}\text { Those who were currently abusing } \\
\text { had a greater magnitude of } \\
\text { attentional biases. }\end{array}$ \\
\hline Bearre et al. (2007) [9] & $\begin{array}{l}\text { Substance dependency/amount of } \\
\text { substance used }\end{array}$ & $\begin{array}{l}\text { Reported a relationship between } \\
\text { dependence severity (based on } \\
\text { the monthly frequency of heroin } \\
\text { used, via inhalation or injection) } \\
\text { and the overall attentional biases. }\end{array}$ \\
\hline MacLean et al. (2018) [5] & $\begin{array}{l}\text { Substance dependency/amount of } \\
\text { substance used }\end{array}$ & $\begin{array}{l}\text { Individuals with diagnosed opioid } \\
\text { dependence exhibited attentional } \\
\text { biases, but these were not found in } \\
\text { non-dependent } \\
\text { prescription-opioid users }\end{array}$ \\
\hline Anderson et al. (2013) [15] & $\begin{array}{l}\text { Impulsiveness and visual } \\
\text { working-memory capacity }\end{array}$ & $\begin{array}{c}\text { Found attentional biases to be } \\
\text { positively related to impulsiveness, } \\
\text { but negatively related to the visual } \\
\text { working memory capacity }\end{array}$ \\
\hline Water et al. (2012) [16] & Cravings & $\begin{array}{c}\text { Elevated attentional biases during } \\
\text { the temptation episodes, and, } \\
\text { the magnitude of biases was } \\
\text { elevated } 1 \mathrm{~h} \text { prior to } \\
\text { the temptation episode }\end{array}$ \\
\hline Garland (2013) [11] & Stimulus timings presented in task & $\begin{array}{l}\text { Reported that attentional biases } \\
\text { were present only when stimuli } \\
\text { were presented for short intervals } \\
\text { of } 200 \text { milliseconds, instead of } \\
2000 \text { milliseconds. }\end{array}$ \\
\hline
\end{tabular}

\section{Attentional Bias in Cannabis-Use Disorders}

For cannabis-use disorders, there is also evidence that both the severity of dependence and the quantity of cannabis consumed affect the magnitude of the underlying attentional biases. In their meta-analysis, O'Neill et al. (2020) [6], highlighted that there was a greater magnitude of attentional bias towards cannabis stimuli observed in cannabis users. More specifically, prior studies, such as that of Field et al. (2005) [12] reported that it is not just the frequency of use, but also the number of joints smoked that affect the absolute magnitude of attentional biases. In two studies by Cousijin et al. (Cousijin et al. (2011) [17] and Cousijin et al. (2013) [18]), they reported there being attentional biases mainly amongst heavy-users. Cousijin et al. (2013) [18] also highlighted that individuals who were clinically categorized as dependent exhibited a stronger magnitude of attentional bias compared to those who were using cannabis heavily but were not dependent. In the study by Campbell et al. (2018) [19] to differentiate between users' and non-users' attentional biases, they also reported that the intensity of cannabis used (grams used per week), correlated with the number of errors made during the testing process, and hence affected the magnitude of attentional biases.

Other studies have highlighted that the duration of the stimulus timings, subjective cravings, perceived stress, and the nature of the stimuli presented may also impact on attentional biases in cannabis users. Vujanovic et al. (2016) [20] reported that individuals with cannabis-use disorder, have had larger attentional biases when they are presented with stimuli for short timings, such as 
125 milliseconds. This finding were also been reported in the meta-analysis by O'Neill et al. (2020) [6], in which they described larger effects when the stimulus was presented for short timing intervals of 125 to 500 milliseconds. Presentation at short stimulus timings has been known to better assess for initial orientation attentional biases. With regards to subjective cravings, Field et al. (2005) [21] reported there being a correlation between the frequency of cannabis use and subjective craving, and this in turn would affect the magnitude of attentional biases. Vujanovic et al. (2016) [20] reported that individuals with cannabis use disorder, who have a significantly greater attentional bias, have higher levels of both perceived stress and acute stress. Wilcockson et al. (2016) [22] reported that the presentation of anxiety-related stimuli would result in heightened attentional-avoidance behavior. Table 2 provides a brief overview of the articles identified and the factors highlighted in cannabis-use disorders.

Table 2. Overview of individual differences and factors modulating biases in cannabis-use disorders.

\begin{tabular}{|c|c|c|}
\hline Studies & $\begin{array}{c}\text { Individual Differences/Factors } \\
\text { Modulating }\end{array}$ & Main Findings \\
\hline O'Neill et al. (2020) [6] & $\begin{array}{l}\text { Amount of substance } \\
\text { used/substance dependency }\end{array}$ & $\begin{array}{c}\text { Greater magnitude of attentional } \\
\text { bias towards cannabis stimuli } \\
\text { observed in cannabis users }\end{array}$ \\
\hline Field et al. (2005) [12] & $\begin{array}{l}\text { Amount of substance } \\
\text { used/substance dependency }\end{array}$ & $\begin{array}{l}\text { Reported that it is not just } \\
\text { the frequency of use, but also } \\
\text { the number of joints smoked that } \\
\text { affect the absolute magnitude of } \\
\text { attentional biases }\end{array}$ \\
\hline Cousijin et al. (2013) [17] & $\begin{array}{l}\text { Amount of substance } \\
\text { used/substance dependency }\end{array}$ & $\begin{array}{l}\text { Highlighted that individuals who } \\
\text { were clinically categorized as } \\
\text { dependent exhibited a stronger } \\
\text { magnitude of attentional bias } \\
\text { compared to those who were } \\
\text { using cannabis heavily but were } \\
\text { not dependent }\end{array}$ \\
\hline Campbell et al. (2018) [19] & $\begin{array}{l}\text { Amount of substance } \\
\text { used/substance dependency }\end{array}$ & $\begin{array}{l}\text { Reported that the intensity of } \\
\text { cannabis used (grams used per } \\
\text { week), correlated with the number } \\
\text { of errors made during the testing } \\
\text { process, and hence affected } \\
\text { the magnitude of } \\
\text { attentional biases. }\end{array}$ \\
\hline Vujanovic et al. (2016) [20] & Stimulus timings & $\begin{array}{l}\text { Reported that individuals with } \\
\text { cannabis use disorder, have had } \\
\text { larger attentional biases when they } \\
\text { are presented with stimulus for } \\
\text { short timings, such as } \\
125 \text { milliseconds }\end{array}$ \\
\hline Field et al. (2005) [21] & Cravings & $\begin{array}{l}\text { Reported there being a correlation } \\
\text { between the frequency of cannabis } \\
\text { use and subjective craving, } \\
\text { and this in turn would affect } \\
\text { the magnitude of attentional biases }\end{array}$ \\
\hline Wilcockson et al. (2016) [22] & Nature of stimuli & $\begin{array}{l}\text { Reported that the presentation of } \\
\text { anxiety-related stimuli would } \\
\text { result in heightened } \\
\text { attentional-avoidance behavior }\end{array}$ \\
\hline
\end{tabular}




\section{Attentional Bias in Stimulant-Use Disorders (Cocaine Use)}

For stimulant-use disorders, there appears to be a correlation between the severity of the substance dependence and attentional biases similar to that observed for opioid and cannabis-use disorders. Marks et al. (2014) [23] measured the fixation time for the computation of attentional biases and reported that only individuals who have had previously used cocaine had underlying attentional biases. They also reported that the magnitude of the attentional biases was correlated with the lifetime use of cocaine.

Apart from severity and quantity of substance use, other factors such as cravings, whether individuals were treatment-seeking, had underlying impulsivity, or were taking other substances or prescribed medications also modulated the magnitude of attentional biases. The association between craving severity ratings and attentional biases was first demonstrated by Copersino et al. (2004) [24]. Their study examined the relationship between attentional bias and cravings amongst individuals with cocaine dependence and a comorbidity of schizophrenia. Vadhan et al. (2007) [25] observed a relationship between attentional bias and whether cocaine-using individuals were treatment-seekers, with treatment-seeking individuals tending to have greater attentional biases, as they had increased response latency and made more errors in identifying the colors of the stimulus presented. Personality characteristics such as impulsivity have been correlated with heightened attentional biases amongst cocaine users (Liu et al. 2011) [26]. With regard to whether other stimuli could modulate attentional biases, there are mixed findings. Montgomery et al. (2010) [27] reported that cocaine users, who were given alcohol, had increased attentional biases for cocaine stimuli, compared to non-users and individuals who merely received placebo. However, Marks et al. in 2015 [28,29] found that the administration of alcohol did not affect attentional biases, but it did affect cravings for cocaine use (Marks et al., 2015) [28]. Table 3 provides a brief overview of the articles identified and the factors highlighted in cannabis-use disorders.

Table 3. Overview of individual differences and factors modulating biases in stimulant-use disorders.

\begin{tabular}{|c|c|c|}
\hline Studies & $\begin{array}{c}\text { Individual Differences/Factors } \\
\text { Modulating }\end{array}$ & Main Findings \\
\hline Marks et al. (2014) [23] & $\begin{array}{l}\text { Substance dependency/amount } \\
\text { of substance used }\end{array}$ & $\begin{array}{l}\text { Reported that only individuals } \\
\text { who have had previously used } \\
\text { cocaine had underlying } \\
\text { attentional biases. }\end{array}$ \\
\hline Copersino et al. (2004) [24] & Cravings & $\begin{array}{l}\text { Reported an association between } \\
\text { craving severity ratings and } \\
\text { attentional biases }\end{array}$ \\
\hline Vadhan et al. (2007) [25] & $\begin{array}{l}\text { Treatment-seeking versus } \\
\text { non-treatment seeking }\end{array}$ & $\begin{array}{l}\text { Reported treatment-seeking } \\
\text { individuals tending to have } \\
\text { greater attentional biases, as they } \\
\text { have had increased response } \\
\text { latency and made more errors in } \\
\text { identifying the colors of } \\
\text { the stimulus presented }\end{array}$ \\
\hline Liu et al. 2011 [26] & Impulsivity & $\begin{array}{c}\text { Impulsivity has been correlated } \\
\text { with heightened attentional biases } \\
\text { amongst cocaine users }\end{array}$ \\
\hline
\end{tabular}

\section{Implications for Clinical Care and Future Research}

It is evident that several individual differences affect the magnitude of biases. Across opioid, cannabis, and stimulant-use disorders, the most common factors identified were the severity of the dependence and the quantity of substance used. The identification of this factor is pertinent for clinical management and for research in the future. In the clinical setting, it may be that there are no 
biases amongst patients who are abusing substances recreationally, or who are in the experimental stage of substance use, but rather in those diagnosed as being dependent and who are using substances frequently. Clinicians thus need to be aware of these individual differences and refer appropriate patients for bias modification interventions (i.e., interventions focused on retraining biases away from the stimuli of interest). In this way, clinicians can personalize interventions for participants, so that only appropriate patients are referred for bias modification intervention, whilst those who do not have biases are referred for conventional psychosocial interventions.

In the research setting, it is our opinion that the identification of these individual differences has resultant implications for bias-modification interventions. Researchers ought to be cognizant of the factors modulating attentional biases and recognize that these factors will help inform the inclusion and exclusion criteria for future research studies attempting to determine the effectiveness of bias modification interventions. This also calls for a more detailed understanding of the patients' substance use prior to their enrolment into future trials. Tools such as the addiction-severity index may help researchers to have a greater understanding of the nature of the substances that participants have abused previously, and the quantity and frequency of their use of substances within the recent month, or in the past year. Based on the studies we highlighted, we have not observed there being a consistency in assessing for baseline biases before participants are enrolled into research involving bias modification. This article, by highlighting all the factors that modulate baseline biases, thus provides good evidence purporting the need for baseline assessment, before patients are recruited into bias-modification interventions.

It is our opinion that future research ought to carefully consider the nature of the visual probe paradigm which is used and, the stimulus timings used. For both opioid and cannabis disorders the timings of stimulus presentation influence the detection of attentional biases, it appears that short stimulus timings are better able to detect attentional biases. It is recognized that short stimulus timings are better able to assess initial orientation to the stimulus, whilst long stimulus intervals are better for detecting delayed engagement [30]. The differences in the performance values of short and long stimulus timings in detecting attentional biases brings into question issues of reliability of the visual probe task. Its internal reliability was first questioned by Ataya et al. (2012) [31], when reporting on laboratory studies with poor internal consistency. Subsequently Field et al. (2012) [32] argued that the poor reliability of the visual probe task might be due to the nature of the stimulus used. In their study, they presented participants with images of their preferred drinks and reported an increase in the magnitude of the attentional biases detected. Further reports show that the reliability of the visual probe task (both the spilt-half and test-retest reliability) has been poor [31]. Last year Zhang et al. (2019) [33] reported extensive variation in the visual probe paradigms that have been used across different studies. This heterogeneity of methods has implications for both existing findings and their inclusion in metanalyses, as well as the research of the future. Moving forward we need to investigate if variations in the task parameters, such as the stimulus timings could improve the reliability of the task, (given that it has been shown that at short stimulus intervals, biases are more readily detected). Another important area for exploration is whether personalization of the stimulus would bring about increased reliability. Jones et al. (2018) [34] investigated the effects of personalization of the stimulus images but reported that this did not improve the reliability of the task. However, Jones et al. (2018) used images that were based on the earlier work of Christiansen et al. (2015) [35] rather than images specifically selected in the study's context. Christensen et al. (2015) [35] had used informal focus groups to select the images to use with their study participants. In future research we need to explore different ways of selecting images to be used in the visual probe task, and whether personalization of the task enhances its effectiveness.

With concerns raised about the reliability of the visual probe task we need to consider whether other more reliable tools should be utilized, for example the direct assessment of biases by the measurement of eye fixation times [36]. The alternative tools are more cumbersome when compared to the conventional 
visual probe task and may be more difficult to use in a clinical setting, but technology perhaps can be harnessed to achieve something which is more reliable and practical.

It is also evident that other variables affecting the magnitude of attentional biases are under-investigated. In the clinical setting, it is not uncommon to manage patients who have abused multiple substances and no existing studies have examined how the use of several drugs impacts on biases. Similarly, no one has examined how factors, such as the mechanisms of use, the duration of use, and the duration of abstinence affect attentional biases. To date the demographic variables of gender and education have been discounted as variables that modulate attentional biases in those with opioid-use disorders. We still need to examine how other demographic variables, including age, affect these biases. These studies could be combined with studies exploring how attentional bias differs amongst treatment-seeking and non-treatment seeking participants, an interesting observation from a single study which needs to be replicated in a variety of substance-use disorders.

\section{Conclusions}

The discovery of these individual differences and factors of the task paradigm that affect the magnitude of attentional biases will help in the future conceptualization of attention-bias-modification intervention. Clinically, it will guide appropriate referral, and the identification of these individual differences will affect the formulation of the inclusion and exclusion criteria for randomized trials.

Author Contributions: M.Z., D.S.S.F., and H.S. jointly conceptualized the study. M.Z. wrote up the first draft of the manuscript, with guidance from D.S.S.F. and H.S. H.S. amended the second draft, which M.Z. worked on further. All authors have read and agreed to the published version of the manuscript.

Funding: M.Z. is supported by a grant under the Singapore Ministry of Health's National Medical Research Council (grant number NMRC/Fellowship/0048/2017) for PhD training. The funding source was not involved in any part of this project.

Conflicts of Interest: None of the authors have any competing interests.

\section{References}

1. Jones, E.B.; Sharpe, L. Cognitive bias modification: A review of meta-analyses. J. Affect. Disord. 2017, 223, 175-183. [CrossRef] [PubMed]

2. Field, M.; Marhe, R.; Franken, I.H. The clinical relevance of attentional bias in substance use disorders. CNS Spectr. 2014, 19, 225-230. [CrossRef] [PubMed]

3. Stacy, A.W.; Wiers, R.W. Implicit cognition and addiction: A tool for explaining paradoxical behavior. Annu. Rev. Clin. Psychol. 2010, 6, 551-575. [CrossRef] [PubMed]

4. Zhang, M.W.B.; Ying, J.; Wing, T.; Song, G.; Fung, D.S.S.; Smith, H.E. Cognitive Biases in Cannabis, Opioid, and Stimulant Disorders: A Systematic Review. Front. Psychiatry 2018, 9, 376. [CrossRef] [PubMed]

5. MacLean, R.R.; Sofuoglu, M.; Brede, E.; Robinson, C.; Waters, A.J. Attentional bias in opioid users: A systematic review and meta-analysis. Drug Alcohol Depend. 2018, 191, 270-278. [CrossRef]

6. O'Neill, A.; Bachi, B.; Bhattacharyya, S. Attentional bias towards cannabis cues in cannabis users: A systematic review and meta-analysis. Drug Alcohol Depend. 2019, 206, 107719. [CrossRef]

7. Zhang, M.; Ying, J.; Amron, S.B.; Mahreen, Z.; Song, G.; Fung, D.S.S.; Smith, H.E. A Smartphone Attention Bias App for Individuals with Addictive Disorders: Feasibility and Acceptability Study. JMIR Mhealth Uhealth 2019, 7, e15465. [CrossRef]

8. Zhang, M.; Ying, J.; Amron, S.B.; Mahreen, Z.; Song, G.; Fung, D.S.; Smith, H.E. Making Sense of Negative Findings from Mobile Attention Bias Modification Interventions for Individuals with Addictive Disorders: Quantitative Feasibility Study. JMIR Mhealth Uhealth 2019, 7, e16325. [CrossRef]

9. Bearre, L.; Sturt, P.; Bruce, G.; Jones, B.T. Heroin-related attentional bias and monthly frequency of heroin use are positively associated in attenders of a harm reduction service. Addict. Behav. 2007, 32, 784-792. [CrossRef]

10. Fadardi, J.S.; Ziaee, S.S. A comparative study of drug-related attentional bias: Evidence from Iran. Exp. Clin. Psychopharmacol. 2010, 18, 539-545. [CrossRef] 
11. Garland, E.L.; Froeliger, B.E.; Passik, S.D.; Howard, M.O. Attentional bias for prescription opioid cues among opioid dependent chronic pain patients. J. Behav. Med. 2013, 36, 611-620. [CrossRef] [PubMed]

12. Field, M.; Eastwood, B.; Bradley, B.P.; Mogg, K. Selective processing of cannabis cues in regular cannabis users. Drug Alcohol Depend. 2006, 85, 75-82. [CrossRef]

13. Dennis-Tiwary, T.A.; Egan, L.J.; Babkirk, S.; Denefrio, S. For whom the bell tolls: Neurocognitive individual differences in the acute stress-reduction effects of an attention bias modification game for anxiety. Behav. Res. Ther. 2016, 77, 105-117. [CrossRef]

14. Constantinou, N.; Morgan, C.J.; Battistella, S.; O’Ryan, D.; Davis, P.; Curran, H.V. Attentional bias, inhibitory control and acute stress in current and former opiate addicts. Drug Alcohol Depend. 2010, 109, 220-225. [CrossRef]

15. Anderson, B.A.; Faulkner, M.L.; Rilee, J.J.; Yantis, S.; Marvel, C.L. Attentional bias for nondrug reward is magnified in addiction. Exp. Clin. Psychopharmacol. 2013, 21, 499-506. [CrossRef] [PubMed]

16. Waters, A.J.; Marhe, R.; Franken, I.H. Attentional bias to drug cues is elevated before and during temptations to use heroin and cocaine. Psychopharmacology 2012, 219, 909-921. [CrossRef] [PubMed]

17. Cousijn, J.; Goudriaan, A.E.; Wiers, R.W. Reaching out towards cannabis: Approach-bias in heavy cannabis users predicts changes in cannabis use. Addiction 2011, 106, 1667-1674. [CrossRef]

18. Cousijn, J.; Watson, P.; Koenders, L.; Vingerhoets, W.A.; Goudriaan, A.E.; Wiers, R.W. Cannabis dependence, cognitive control and attentional bias for cannabis words. Addict. Behav. 2013, 38, 2825-2832. [CrossRef]

19. Campbell, D.W.; Stewart, S.; Gray, C.E.P.; Ryan, C.L.; Fettes, P.; McLandress, A.J.; Dell'Aquila, R. Chronic cannabis use and attentional bias: Extended attentional capture to cannabis cues. Addict. Behav. 2018, 81, 17-21. [CrossRef]

20. Vujanovic, A.A.; Wardle, M.C.; Liu, S.; Dias, N.R.; Lane, S.D. Attentional bias in adults with cannabis use disorders. J. Addict. Dis. 2016, 35, 144-153. [CrossRef]

21. Field, M. Cannabis 'dependence' and attentional bias for cannabis-related words. Behav. Pharmacol. 2005, 16, 473-476. [CrossRef] [PubMed]

22. Wilcockson, T.D.W.; Sanal, N.E.M. Heavy cannabis use and attentional avoidance of anxiety-related stimuli. Addict. Behav. Rep. 2016, 3, 38-42. [CrossRef] [PubMed]

23. Marks, K.R.; Roberts, W.; Stoops, W.W.; Pike, E.; Fillmore, M.T.; Rush, C.R. Fixation time is a sensitive measure of cocaine cue attentional bias. Addiction 2014, 109, 1501-1508. [CrossRef] [PubMed]

24. Copersino, M.L.; Serper, M.R.; Vadhan, N.; Goldberg, B.R.; Richarme, D.; Chou, J.C.; Stitzer, M.; Cancro, R. Cocaine craving and attentional bias in cocaine-dependent schizophrenic patients. Psychiatry Res. 2004, 128, 209-218. [CrossRef]

25. Vadhan, N.P.; Carpenter, K.M.; Copersino, M.L.; Hart, C.L.; Foltin, R.W.; Nunes, E.V. Attentional bias towards cocaine-related stimuli: Relationship to treatment-seeking for cocaine dependence. Am. J. Drug Alcohol Abuse 2007, 33, 727-736. [CrossRef] [PubMed]

26. Liu, S.; Lane, S.D.; Schmitz, J.M.; Waters, A.J.; Cunningham, K.A.; Moeller, F.G. Relationship between attentional bias to cocaine-related stimuli and impulsivity in cocaine-dependent subjects. Am. J. Drug Alcohol Abuse 2011, 37, 117-122. [CrossRef]

27. Montgomery, C.; Field, M.; Atkinson, A.M.; Cole, J.C.; Goudie, A.J.; Sumnall, H.R. Effects of alcohol preload on attentional bias towards cocaine-related cues. Psychopharmacology 2010, 210, 365-375. [CrossRef]

28. Marks, K.R.; Pike, E.; Stoops, W.W.; Rush, C.R. Alcohol Administration Increases Cocaine Craving but Not Cocaine Cue Attentional Bias. Alcohol Clin. Exp. Res. 2015, 39, 1823-1831. [CrossRef]

29. Marks, K.R.; Pike, E.; Stoops, W.W.; Rush, C.R. The magnitude of drug attentional bias is specific to substance use disorder. Psychol. Addict. Behav. 2015, 29, 690-695. [CrossRef]

30. Lopes, F.M.; Viacava, K.R.; Bizarro, L. Attentional bias modification based on visual probe task: Methodological issues, results and clinical relevance. Trends Psychiatry Psychother. 2015, 37, 183-193. [CrossRef]

31. Ataya, A.F.; Adams, S.; Mullings, E.; Cooper, R.M.; Attwood, A.S.; Munafo, M.R. Internal reliability of measures of substance-related cognitive bias. Drug Alcohol Depend. 2012, 121, 148-151. [CrossRef] [PubMed]

32. Field, M.; Christiansen, P. Commentary on, 'Internal reliability of measures of substance-related cognitive bias'. Drug Alcohol Depend. 2012, 124, 189-190. [CrossRef] [PubMed]

33. Zhang, M.; Fung, D.S.S.; Smith, H. Variations in the Visual Probe Paradigms for Attention Bias Modification for Substance Use Disorders. Int. J. Environ. Res. Public Health 2019, 16, 3389. [CrossRef] [PubMed] 
34. Jones, A.; Christiansen, P.; Field, M. Failed attempts to improve the reliability of the alcohol visual probe task following empirical recommendations. Psychol. Addict. Behav. 2018, 32, 922-932. [CrossRef] [PubMed]

35. Christiansen, P.; Mansfield, R.; Duckworth, J.; Field, M.; Jones, A. Internal reliability of the alcohol-related visual probe task is increased by utilising personalised stimuli and eye-tracking. Drug Alcohol Depend. 2015, 155, 170-174. [CrossRef] [PubMed]

36. Zhang, M.W.; Ying, J.B.; Song, G.; Fung, D.S.S.; Smith, H.E. Recent Advances in Attention Bias Modification for Substance Addictions. Int. J. Environ. Res. Public Health 2018, 15, 676. [CrossRef] [PubMed]

Publisher's Note: MDPI stays neutral with regard to jurisdictional claims in published maps and institutional affiliations.

(C) 2020 by the authors. Licensee MDPI, Basel, Switzerland. This article is an open access article distributed under the terms and conditions of the Creative Commons Attribution (CC BY) license (http://creativecommons.org/licenses/by/4.0/). 